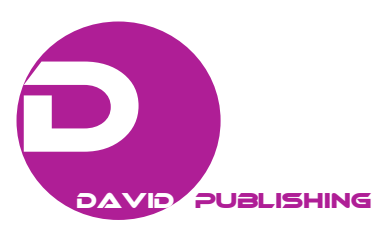

\title{
Reduction of Nitro Compounds, Through different Reaction Conditions (Combinatory Chemistry)
}

\author{
Lejarazo Gómez Eva F., Santos Santos Elvira and Suarez Torres Sara \\ Dept. of Organic Chemistry, Unit of Graduate Studies, School of Chemistry, UNAM, University City, Circuito interior, Delegación \\ Coyoacán, University City. School of Chemistry 04510, Mexico City, Mexico
}

\begin{abstract}
In this work we intend to approach the study of the chemo-selectivity of a transformation on a polyfunctional compound. An example of how the result of a reaction depends on experimental conditions, different nitrated compounds reduction, will be shown. The reduction reaction was carried out under different conditions found in the literature; they were applied to 1,3-dinitrobenzene and to 4-nitroacetophenone. The reduction conditions were: $\mathrm{Zn} / \mathrm{NH}_{4} \mathrm{Cl}$, hydrazine and $10 \% \mathrm{Pd} / \mathrm{C}, \mathrm{NaBH} 4$ and $10 \%$ $\mathrm{Pd} / \mathrm{C}$ in water, $\mathrm{Sn} / \mathrm{HCl}, \mathrm{NaBH}_{4} /$ ethanol, $\mathrm{Na}_{2} \mathrm{Sx} \cdot 9 \mathrm{H}_{2} \mathrm{O}$-sulfur $(0.2 \mathrm{~g}$ to $1.0 \mathrm{~g})$ at different time periods. These reagents preferably affect one of the functional groups present.
\end{abstract}

Key word: Reduction of nitro compounds.

\section{Introduction}

There are various forms of reduction for the formation of amines from nitro compounds, including: (a) reduction with a metal in an acid medium [1]; (b) use of ammonium sulphides [2], and (c) hydrogenation of catalytic transfer, within which systems are known as: (1) $\mathrm{NH}_{4} \mathrm{Cl} / \mathrm{Zn}$ in aqueous medium [3, 4], (2) cyclohexane/Pd [5], and even (3) $\mathrm{Mg} / \mathrm{H}_{2} \mathrm{~N}-\mathrm{NH}_{2}$ [6]. The mentioned articles indicate that the described methods achieve a high selectivity [7] and high yields in the reduction of the nitro group, in the presence of other functional groups, so we were interested in applying these methods in the teaching laboratories of Experimental Organic Chemistry III; taking advantage of the fact that in a single laboratory session, thanks to the application of combinatorial chemistry in the form of synthesis in parallel, we could try all the mentioned methods.

Although some of them require very strong acidic media or generate highly toxic products, such as ammonia or sulfides that have a negative impact on

Corresponding author: Eva Florencia Lejarazo Gómez, associate technician "B", research field: chemistry. the environment or present difficulties in their experimental handling such as: catalytic hydrogenation $[8,9]$. Although sodium borohydride is a reducing agent widely used to reduce carbonyls, however, Petrini [10] describes the reduction of nitrous groups to amines with $10 \% \mathrm{NaBH}_{4} / \mathrm{Pd} / \mathrm{C}$ in $\mathrm{THF}$, at room temperature, with a yield of $70 \%$ to $90 \%$, which is why it was an option to consider. Wade [11] escribes the use of sodium borohydride in the presence of $\mathrm{Ni}$ to reduce nitro groups to amino groups, it is also described that with biguanidine complexes with cobalt III, they achieve the same objective.

Non catalyzed reductions are generally limited to reduce the carbonyl groups, imino and hydroperoxide. Systems based on reductions catalyzed have greatly expanded the use of sodium borohydride, have expanded the chemical properties when combined with the use of inorganic cations, anions, and organometallic complexes.

There are several different types of catalysts or co-reactants and the mechanisms by which borohydride act. The slight variations in these systems can greatly affect the chemo or regio-selectivity of the reductions and the resulting products. These areas are 
indicated. The reductions catalyzed with borohydride are presented by the functional groups that are reduced.

There are known antecedents of the use of reducing systems with conventional heating in the reduction of nitro groups [12] with good results. There is also the case for the chemoselective reduction of 4-nitroacetophenone, a compound with two reducible groups (nitro and carbonyl). In the first part, the aromatic nitro group is reduced to aromatic amine using tin and hydrochloric acid, a reagent commonly used for transformation and one that does not reduce carbonyl groups. In the second part, the ketone is reduced using the mild hydride transfer agent, sodium borohydride [13]. Many of the authors report the products obtained, but they do not report the melting point, nor the yield.

In Experimental Organic Chemistry, in the chapter corresponding to reduction of nitrated derivatives, 1,3-dinitrobenzene is generally used with sodium polysulfide, the idea is to show a selective reduction. The use of other nitrated products or other reducers is not explored, so students consider that there is only one molecule to reduce, a single reducer, and students do not acquire the good habit of consulting the bibliography in relation to the reduction process and looking up which is more adaptable to the conditions of the laboratory, nor do they compare the results obtained, with those always described in the manuals. Due to the aforementioned, it was decided to use two nitrated compounds with eight reduction systems.

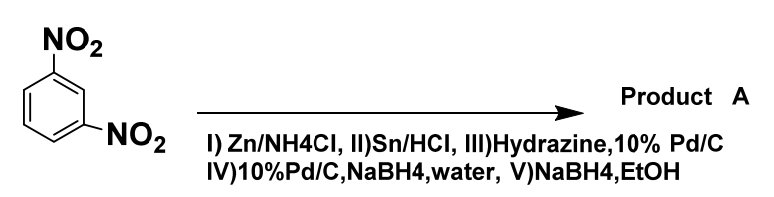

Each student reduces a molecule with a different reagent, later in a seminar, the students present their results and all analyze the effect of using several nitrated compounds with several reducers. So, the students discuss the results of the experiments and if the academics objectives planned coincide with the results found.

The experimental conditions of reduction of nitro compounds were searched in the literature and the different methods of reduction were experimentally tested. The results obtained with the reduction systems and the nitro compounds used are presented. All this is carried out fulfilling some of the principles of green chemistry and following a chemistry protocol friendly to the environment [14].

(see Table No. I).

\section{Materials and Method}

\subsection{Apparatus}

The melting points were determined by open capillary method and uncorrected.

Infrared spectra were recorded on FTIR Nicolet, Impact 410 using $\mathrm{KBr}$.

\subsection{Chemicals and Reagents}

Zinc, ammonium chloride, hydrazine and $10 \%$ $\mathrm{Pd} / \mathrm{C}$., $\mathrm{NaBH}_{4}$ and $10 \% \mathrm{Pd} / \mathrm{C}$., water, $\mathrm{Sn} / \mathrm{HCl}$, $\mathrm{Na}_{2} \mathrm{Sx} \cdot 9 \mathrm{H}_{2} \mathrm{O}$-sulfur, $\quad \mathrm{NaBH}_{4} /$ ethanol, 4-nitroacetophenone, 1,3-dinitrobenzene, $6 \mathrm{M}$ hydrochloric acid, ethanol, celite.

\subsection{Scheme of Synthesis}

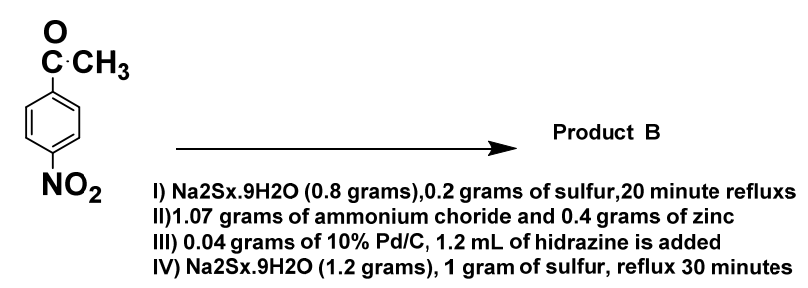




\section{Synthesis of Compounds}

\subsection{Preparation of 4-Aminoacetophenone $\mathrm{NH}_{4} \mathrm{Cl} / \mathrm{Zn}$ (Reaction I)}

(1) In a $125 \mathrm{~mL}$ ball flask with ground joint, place a magnetic bar, weigh $0.3 \mathrm{~g}$. of 4-nitroacetophenone, $1.07 \mathrm{~g}$ of ammonium chloride, add $5 \mathrm{~mL}$ of water for 15 minutes, bubble nitrogen, add $0.4 \mathrm{~g}$ of Zinc. (2) Place the flask on a hot plate, place a reflux condenser for 1 hour at room temperature with vigorous stirring (3) Filter on a Buchner funnel containing a layer of celite. (4) The filtrate is evaporated; the solid obtained is filtered, dried, weighed; thin-layer chromatography is carried out, using the raw material as reference; determine the melting point and calculate the crude yield.

\subsection{Preparation of 4-Aminoacetophenone with $\mathrm{Sn} / \mathrm{HCl}$ Reducing System (Reaction II)}

(1) In a $125 \mathrm{~mL}$ flat bottomed spherical flask with ground joint, place $7.5 \mathrm{mmol}$ of 4-nitroacetophenone and $10.2 \mathrm{mmol}$ of granular tin and a magnetic stirrer. (2) $21.6 \mathrm{~mL}$ of $6 \mathrm{~N} \mathrm{HCl}$ is added slowly through an addition funnel and a water coolant is placed in the mouth of the flask. (3) Shake vigorously with the magnetic stirrer. (4) Heat to reflux for one hour, until most of the tin has dissolved. Verify that the $\mathrm{pH}$ is acidic, if it is not the case, acidify and re-heat to reflux until the disappearance of the raw material. (5) Afterwards leave to cool at room temperature and then move to ice-water. (6) $-\mathrm{NaOH}$ $(10 \mathrm{M})$ is added dropwise and with vigorous stirring until $\mathrm{pH}=10$. (7) -Heat to reflux for 7 more minutes, check that the $\mathrm{pH}$ is equal to 10 , and filter hot; preheat the Buchner, filtering $\pm 10 \mathrm{~mL}$ of boiling water. The filtered water is drained. (8) The filtered solid is added little by little a hot mixture (at $70^{\circ}$ approximately) of $20 \mathrm{~mL}$ of ethanol water (2:1) to dissolve the product, since it is adhered to tin and its salts. Weigh the solid that did not dissolve which is constituted by $\mathrm{Sn}+\mathrm{SnO}_{2} \mathrm{n}$; This residue is labeled No.
1. (9) The filtrate (ethanol-hot water with product, from step 8 is cooled in ice-water to precipitate the dissolved product. The product of the reaction is filtered under vacuum; if it is not precipitated, the ethanol is distilled. If the product of the reduction is liquid, it must be extracted with dichloromethane, 3 times with $15 \mathrm{~mL}$ each time. (10) The solid product, which is in the filter (step 9), is washed with cold water, 4 times, $2 \mathrm{~mL}$ each time. It is dried and weighed. (11) If you had to extract (Step 9) with dichloromethane, combine the extracts, wash the solution in dichloromethane with cold water, until $\mathrm{pH}$ =7.0. (12) Dry the dichloromethane with anhydrous $\mathrm{Na}_{2} \mathrm{SO}_{4}$ and distill the solvent until there are $\pm 5 \mathrm{~mL}$; pour with a funnel into a 50 or $100 \mathrm{~mL}$ round beaker, previously weighed. Evaporate until dry and reweigh; by difference, determine the weight of the product of the reaction. (13) When the product in the reaction is solid, the total volume of the filtrate and the washing waters is measured (Steps 9 and 10) and its characteristics are recorded. The above liquids are referred to as Residue No. 2 and must be neutralized with $6 \mathrm{M} \mathrm{HCl}$ and placed in the appropriate residue container. (14) Likewise separate the aqueous phase when it was extracted with dichloromethane (Residue No. 3), write down its characteristics, neutralize it and place it in the waste container (No. 3). (15) For the product of the reaction (product washed with cold water, step 10), the melting point and its IR and NMR spectra is determined, a thin layer chromatography and the structure of the product is established for the reaction. (16) Determine the yield of the crude product and then recrystallize it from ethanol, determine the new yields (for the reaction and the crystallization). (17) If the product of the reaction was extracted with dichloromethane, it will be in the spherical flask (Step 12). Carry out c.c.f, in a mobile phase of Hexane-Ethyl Acetate (30-70), placing as reference the raw material, if it is solid determine the $p$. $f$, and establish its structure and calculate the performance of the reaction. 
3.3 Preparation of 4-Aminoacetophenone with $10 \%$ $P d / C$, Hydrazine (Reaction III)

(1) In a $125 \mathrm{~mL}$ flat-bottomed ball flask with ground joint, containing a magnetic bar, place 0.006 mol of 4-nitroacetophenone, $10 \mathrm{~mL}$ of ethanol, $1 \mathrm{~mL}$ of water, 0.04 grams of $\mathrm{Pd} / \mathrm{C}$ and $1.2 \mathrm{~mL}$ of hydrazine, place a refrigerant in the reflux position in the mouth of the flask. (2) Place on a heating and stirring hot plate, stir vigorously at reflux for 1 hour, filter in a Buchner funnel containing a layer of celite, the mother liquor is brought to $\mathrm{pH}=9.0$, evaporate with the aid of a rotary evaporator, a yellow precipitate residue should ensue. Thin layer chromatography is carried out, using the raw material as reference, determine the melting point, weigh the product and determine yield.

3.4 Preparation of 4-Aminoacetophenone with 10\% $\mathrm{NaBH}_{4} / \mathrm{Pd} / \mathrm{C}$ Reducing System (Reaction IV)

(1) Place in a $125 \mathrm{~mL}$ ball flask with ground joint $0.05 \mathrm{~g}$ of $10 \% \mathrm{Pd} / \mathrm{C}$ in $5 \mathrm{~mL}$ of water, in a $250 \mathrm{~mL}$ flask and add $0.39 \mathrm{~g}(0.010 \mathrm{~mol})$ of $\mathrm{NaBH}_{4}$ in $5 \mathrm{~mL}$ of water, place a magnetic bar. (2) Place nitrogen in the stirring mixture and add a solution of $0.6 \mathrm{~g}(0.0035$ mol) of 4-nitroacetophenone in $13 \mathrm{~mL}$ of $2 \mathrm{M} \mathrm{NaOH}$, verify that the $\mathrm{pH}$ is alkaline. (3) Add drop by drop for 5 minutes, stirring at room temperature, until the color disappears and then filter through a layer of celite, wash it with dichloromethane, acidify the mother liquors until destroying the sodium borohydride (there should no longer be hydrogen evolution), the filtrate is extracted with dichloromethane 3 times with $5 \mathrm{~mL}$ each time, the organic extracts are combined and dried with anhydrous $\mathrm{Na}_{2} \mathrm{SO}_{4}$ anhydrous. (4) Evaporate until dry, the residue is dissolved in $10 \mathrm{~mL}$ of ethanol, filtered; and the filtrate is concentrated until dry, the solid is weighed, the melting point is determined, the yield of crude product is calculated, and a thin layer chromatography is carried out, using the raw material as reference: mobile phase of Hexane-ethyl acetate (30-70).

\subsection{Preparation of 1-(4-nitrophenyl) Ethanol (Reaction V)}

(1) In a $125 \mathrm{ml}$ flat bottom ball flask with ground joint, containing a magnetic bar, place $7.5 \mathrm{mmol}$ of 4-nitroacetophenone, $15 \mathrm{~mL}$ of ethanol; place a coolant in the mouth of the flask. (2) Stir and heat slightly on a hot plate, to increase the solubility of the raw material and then let it cool to room temperature; if the raw material is very soluble, it does not need to be heated. (3) Weigh in a vial $2.28 \mathrm{~g}, 40 \mathrm{mM}$ of $\mathrm{NaBH}_{4}$, keep it covered and add it slowly in more or less three portions, for approximately ten minutes. (4) $24 \mathrm{~mL}$ of water is added and heated to reflux for 1.5 hours; at this time the evolution of hydrogen must already be minimal. Verify by c.c.f. that the raw material has disappeared after the time has elapsed ( 1.5 hours). If hydrogen is still evolving, add $3 \mathrm{M} \mathrm{HCl}$ dropwise until all the $\mathrm{NaBH}_{4}$ has reacted; distill the ethanol, cool and extract (in an appropriate separating funnel) three times with dichloromethane, with $20 \mathrm{~mL}$ portions each time. (5) The total dichloromethane (60 $\mathrm{mL}$, as free of water as possible), dries with anhydrous $\mathrm{Na}_{2} \mathrm{SO}_{4}$ anhydrous, it is filtered into a $100 \mathrm{~mL}$ ball flask, with ground joint, previously weighed, and the solvent is distilled in a rotary evaporator or by simple distillation, obtaining as residue the product of the reaction. (6) The product is weighed with the flask, the difference in product weight determines the reaction weight. Make c .c. f., p.f. if it is solid and carry out spectroscopy, to be able to establish the structure of the product obtained and determine the performance of the reaction.

3.6 Preparation of 1,3-Diaminobenzene with $10 \%$ Pd/C, Hydrazine (Reaction VI)

(1) In a $125 \mathrm{~mL}$ round flask, with a ground joint, weigh 0.336 grams of 1,3-dinitrobenzene, add $10 \mathrm{~mL}$ of ethanol, $1 \mathrm{~mL}$ of water, $0.04 \mathrm{~g}$ of $10 \% \mathrm{Pd} / \mathrm{C}$ and 1.2 $\mathrm{mL}$ of hydrazine. (2) In a $100 \mathrm{~mL}$ beaker weigh $1.07 \mathrm{~g}$ of ammonium chloride, dissolve in $5 \mathrm{~mL}$ of water, stir for 15 minutes. (3) Add $0.4 \mathrm{~g}$ of zinc, bubble nitrogen, 
mix both solutions, shake the mixture vigorously and heat to reflux for 1 hour. (4) Filter in a Buchner funnel, which contains a layer of celite, the filtrate is brought to $\mathrm{pH}=9.0$. (5) Evaporate the solvent in a rotary evaporator, the solid formed, filter, thin-layer chromatography is carried out; using the raw material as reference, the product is weighed, and the melting point is determined.

\subsection{Preparation of 1-Amino 3-Nitroacetophenone with $\mathrm{NH}_{4} \mathrm{Cl} / \mathrm{Zn}$ Reductant System (Reaction VII)}

(1) In a $125 \mathrm{~mL}$ ball flask with ground joint, place a magnetic bar, weigh $0.336 \mathrm{~g}$ of 1,3-dinitrobenzene, $1.07 \mathrm{~g}$ of ammonium chloride, add $5 \mathrm{~mL}$ of water for 15 minutes, bubble nitrogen, add $0.4 \mathrm{~g}$ of Zinc. (2) Place the flask on a hot plate, place a reflux condenser for 1 hour at room temperature with vigorous stirring. (3) Filter on a Buchner funnel containing a layer of celite. (4) The filtrate is evaporated; the solid obtained, filtered, dried, weighed, thin-layer chromatography is carried out; using the raw material as reference, determine the melting point and calculate the crude yield.

3.8 Preparation of 1-Amino, 3-Nitrobenzene with a $\mathrm{Na}_{2} \mathrm{~S}_{X} .9 \mathrm{H}_{2} \mathrm{O}$ Reduction System (Reaction VIII)

(1) Prepare a solution of sodium polysulfide, dissolve 4.5 grams of crystallized sodium sulfide $\left(\mathrm{Na}_{2} \mathrm{~S}_{\mathrm{X}} \cdot 9 \mathrm{H}_{2} \mathrm{O}\right)$ in $15 \mathrm{~mL}$ of water. (2) Add 1.0 gram of fine powder sulfur and boil until a clear solution is obtained. (3) In a $125 \mathrm{~mL}$ Erlenmeyer flask, place 2.5 $\mathrm{g}$ of m-dinitrobenzene and $15 \mathrm{~mL}$ of water. (4) Heat the mixture gently and stir until it starts to boil. (5) Add slowly and without stopping stir the sodium polysulfide solution. (6) Boil again for 30 more minutes (do not let the reaction mixture dry, if this happens, add water). (7) Let cool and add $10 \mathrm{~g}$ of ice. A solid is obtained which is filtered under vacuum and washed with cold water, until the wash water is slightly yellow. (8) The solid is transferred to a 125 $\mathrm{mL}$ Erlenmeyer flask containing $15 \mathrm{~mL}$ of water and
$3.5 \mathrm{~mL}$ of concentrated $\mathrm{HCl}$. (9) It is boiled, which dissolves the corresponding aniline, leaving the sulfur and m-dinitrobenzene that has not reacted. (10) Filter hot, the solid is placed in the tray for solid waste. (11) Add a concentrated solution of ammonia to the filtrate until an alkaline $\mathrm{pH}$ has been reached, precipitating the aniline product of the reduction. (12) Filter and recrystallize from boiling water. (13) Determine melting point and carry out a chromatoplate, taking as a reference the raw material. (14) Calculate the yield of the reaction.

3.9 Preparation of 1-Amino, 3-Nitrobenzene with a $\mathrm{Na}_{2} \mathrm{~S}_{\mathrm{X}} \cdot 9 \mathrm{H}_{2} \mathrm{O}$ Reduction System (Reaction IX)

(1) Prepare a solution of sodium polysulfide, dissolving $1.2 \mathrm{~g}$ of crystallized sodium sulfide $\left(\mathrm{Na}_{2} \mathrm{~S}_{\mathrm{X}} \cdot 9 \mathrm{H}_{2} \mathrm{O}\right)$ in $15 \mathrm{~mL}$ of water. (2) Add 1.0 gram of fine powder sulfur and boil until a clear solution is obtained. (3) In a $125 \mathrm{~mL}$ Erlenmeyer flask, 0.8 grams of m-dinitrobenzene and $15 \mathrm{~mL}$ of water are placed. (4) Heat the mixture gently and stir until it starts to boil. (5) Add slowly and without stopping, stir the sodium polysulfide solution. (6) Let boil again for 30 more minutes (do not let the reaction mixture dry, if this happens, add water). (7) Let cool and add 10 grams of ice. A solid is obtained, it is filtered under vacuum and washed with cold water until the wash water is slightly yellow. (8) The solid is transferred to a $125 \mathrm{~mL}$ Erlenmeyer flask containing $15 \mathrm{~mL}$ of water and $3.5 \mathrm{~mL}$ of concentrated $\mathrm{HCl}$. (9) It is boiled, which dissolves the corresponding aniline, leaving the sulfur and m-dinitrobenzene that has not reacted. (10) Hot filter, the solid is placed in the tray for solid waste. (11) To the filtrate a concentrated solution, ammonia is added until alkaline $\mathrm{pH}$, precipitating the aniline product of the reduction. (12) It is filtered and recrystallized from boiling water. (13) Determine the melting point and carry out a chromatoplate, taking as a reference the raw material. (14) Calculate the yield of the reaction. 
Table No. I.

\begin{tabular}{|c|c|c|c|c|c|c|}
\hline $\begin{array}{l}\text { Reaction } \\
\text { No. }\end{array}$ & Raw material & Technique & Characteristics & Yield (\%) & $\begin{array}{l}\text { Product } \\
\text { obtained } \\
\text { experimentally }\end{array}$ & $\begin{array}{l}\text { Expected product } \\
\text { according to literature }\end{array}$ \\
\hline 1 & 4-nitroacetophenone & $\begin{array}{l}0.3 \mathrm{~g} \text { of } \\
\text { 4-nitroacetophenone }+ \\
1.07 \mathrm{~g} \text { of ammonium } \\
\text { chloride }+5 \mathrm{~mL} \text { of water } \\
+0.04 \mathrm{~g} \text { of Zinc }[4,15] \\
\text { Nitrogen is bubbled, } \\
\text { stirred for } 1 \text { hour }\end{array}$ & Yellow solid & $\begin{array}{l}25^{*} \\
\text { p.f }=98-100^{\circ} \mathrm{C}\end{array}$ & $\mathrm{NH}_{2}$ & $\begin{array}{l}\text { Tested only for } \\
\text { nitrobenzene }\end{array}$ \\
\hline 2 & 4-nitroacetophenone & $\begin{array}{l}7.5 \mathrm{mmol} \text { of } \\
\text { 4-nitroacetophenone } \\
\text { material and } 10.2 \mathrm{mmol} \text { of } \\
\text { granular tin, } 6 \mathrm{M}[16] \mathrm{HCl} \\
\text { and a magnetic stirrer }\end{array}$ & Yellow solid & $\begin{array}{l}46.3^{*} \\
\text { p.f }=103-105^{\circ} \mathrm{C}\end{array}$ & $\mathrm{NH}_{2}$ & $\begin{array}{l}\text { p.f=103-6 } 6^{\circ} \mathrm{C} \\
\text { Tested for } \\
\text { 3-nitroacetophenon, no } \\
\text { performance is described. }\end{array}$ \\
\hline 3 & 4-nitroacetophenone & $\begin{array}{l}0.3 \text { grams } \\
4 \text {-nitroacetophenone plus } \\
10 \mathrm{~mL} \text { of ethanol, } 1 \mathrm{~mL} \text { of } \\
\text { water, } 0.04 \mathrm{~g} \text { of } 10 \% \mathrm{Pd} / \mathrm{C} \text {, } \\
1.2 \mathrm{~mL} \text { of hydrazine, heat } \\
\text { to reflux for } 1 \text { hour and the } \\
\text { mother liquor is brought to } \\
\mathrm{pH}=9.0\end{array}$ & Yellow solid & $\begin{array}{l}55.3^{*} \\
\text { p.f }=104-106^{\circ} \mathrm{C}\end{array}$ & $\mathrm{NH}_{2}$ & $\begin{array}{l}\text { p.f }=103-6^{\circ} \mathrm{C} \\
\text { This molecule was used } \\
\text { in the article, they } \\
\text { obtained } 3.6 \% \text {. }\end{array}$ \\
\hline 4 & 4-nitroacetophenone & $\begin{array}{l}\text { Place } 0.05 \mathrm{~g} \text { of } 10 \% \mathrm{Pd} / \mathrm{C} \\
\text { in } 5 \mathrm{~mL} \text { of water, in a } 250 \\
\mathrm{~mL} 3 \text {-neck conical flask } \\
\text { and add } 0.39 \mathrm{~g} \text { of } \mathrm{NaBH}_{4} \\
\text { in } 7.5 \mathrm{~mL} \text { of water, place } \\
\text { a magnetic stirrer. }\end{array}$ & Yellow solid & $\begin{array}{l}66.89 \\
\text { p.f }=104-106^{\circ} \mathrm{C}\end{array}$ & & $\begin{array}{l}\text { Methodology was not } \\
\text { described in the } \\
\text { literature. }\end{array}$ \\
\hline 5 & 4-nitroacetophenone & $\begin{array}{l}7.5 \mathrm{mmol} \text { of } \\
\text { 4-nitroacetophenone, } 15 \\
\mathrm{~mL} \text { of ethanol; add } 2.28 \\
\text { grams or } 40 \mathrm{mM} \text { of } \mathrm{NaBH}_{4} \\
\text { [16], keep it covered, heat } \\
\text { to reflux for } 1.5 \text { hours }\end{array}$ & Yellow liquid & $\begin{array}{l}85.5 \\
\text { liquid }\end{array}$ & 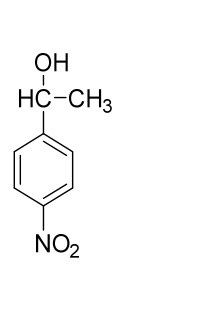 & $\begin{array}{l}\text { Tested for } \\
\text { 3-nitroacetophenon, no } \\
\text { performance is described. }\end{array}$ \\
\hline 6 & 1,3-dinitrobenzene & $\begin{array}{l}\text { 1,3-dinitrobenzene, } 10 \mathrm{~mL} \\
\text { of ethanol, } 1 \mathrm{~mL} \text { of water, } \\
0.04 \mathrm{~g} \text { of } 10 \% \mathrm{Pd} / \mathrm{C}[17], \\
1.2 \mathrm{~mL} \text { of hydrazine is } \\
\text { added, heated to reflux for } \\
1 \text { hour }\end{array}$ & Yellow solid & $\begin{array}{l}37.56^{*} \\
\text { P.f }=64-66^{\circ} \mathrm{C}\end{array}$ & $\mathrm{NH}_{2}$ & $\begin{array}{l}\text { p.f=64-66 }{ }^{\circ} \mathrm{C} \\
\text { The one reported in the } \\
\text { literature, gives the } \\
\text { selective. reduction. }\end{array}$ \\
\hline
\end{tabular}


Table 1 to be continued

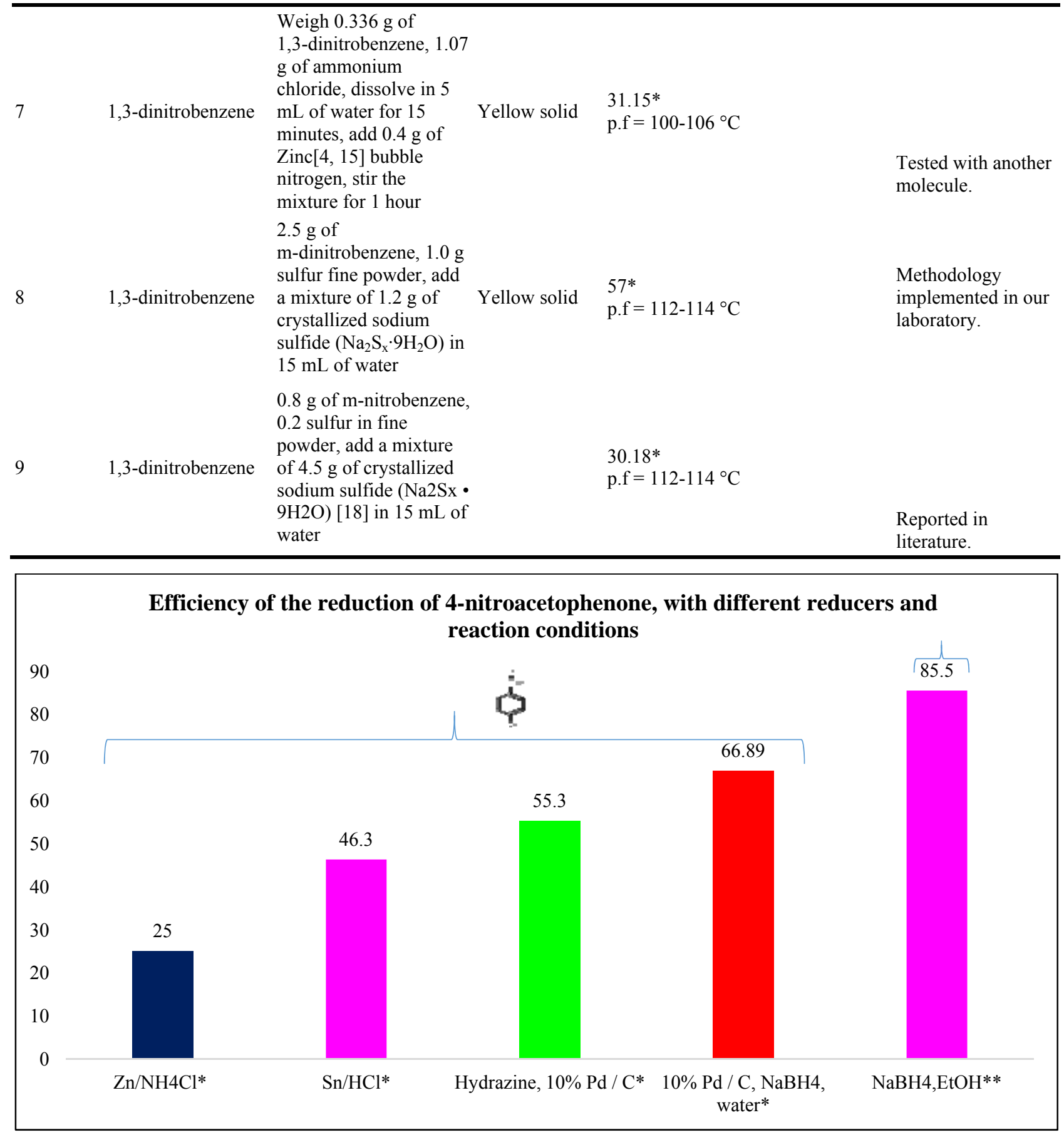

Fig. No. I.

* Obtained as a product of the reaction, the corresponding amino group, the melting point corresponds to that reported in the literature in all cases. 


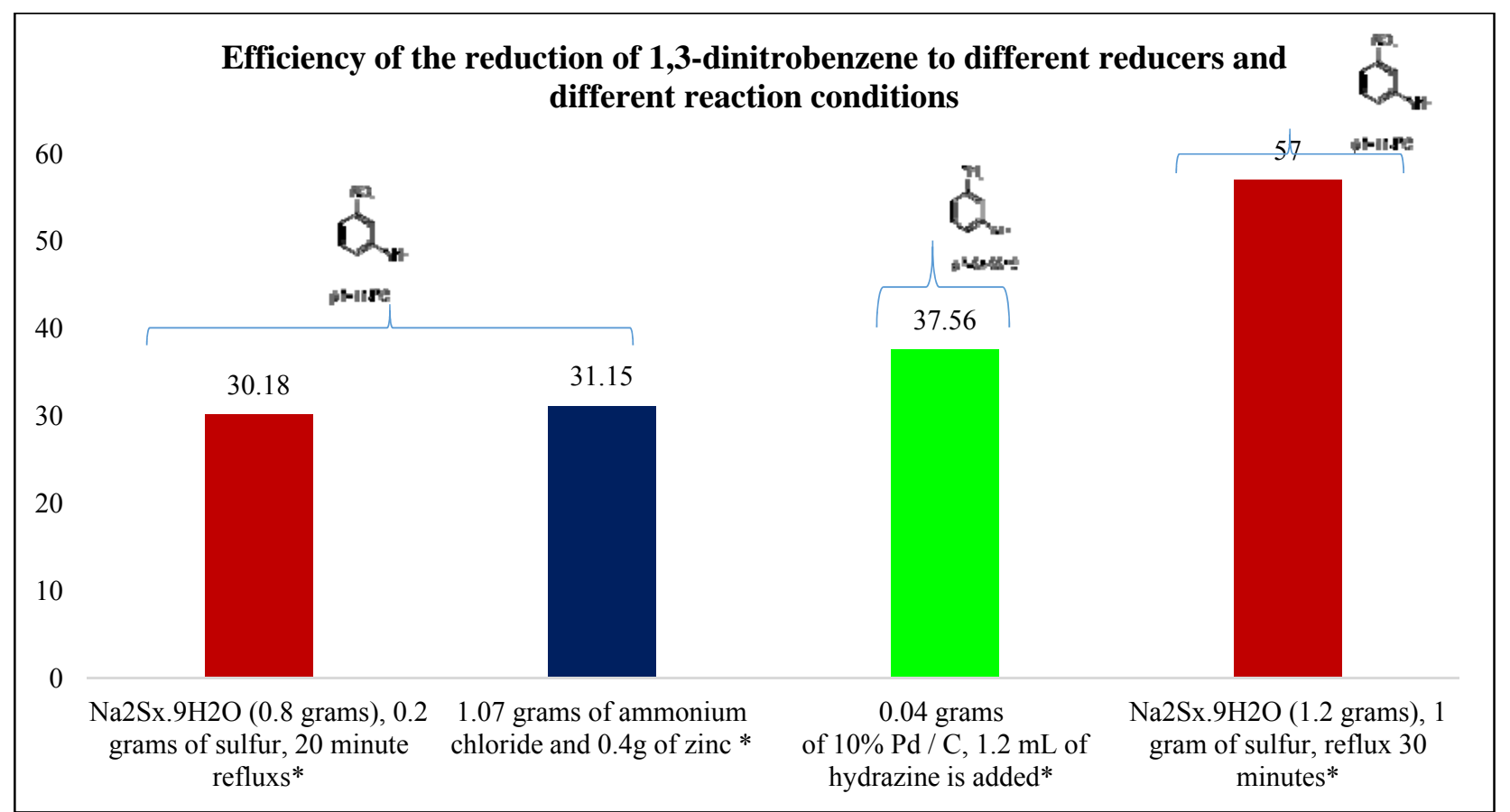

Fig. No. II.

* The product is the reduction of the amino group, since the melting point corresponds to that reported in the literature.

\section{Results and Discussion}

The obtained results are presented in graphic form.

\section{Conclusions}

In Fig. No. I, it is observed that the most efficient reaction to selectively reduce the nitro group is that which uses $10 \% \mathrm{Pd} / \mathrm{C}$, using as a raw material the molecule 4-nitroacetophenone $(66.89 \%)>\mathrm{Pd} / \mathrm{C}$ at $10 \%$, hydrazine $(55.3 \%)>\mathrm{Sn} / \mathrm{HCl}(46.3 \%)>$ $\mathrm{NH} 4 \mathrm{Cl} / \mathrm{Zn}$ (25\%), surprisingly, this molecule does not attack the carbonyl group.

The best efficiency in the reduction was with (NaBH4, ethanol 85.5\%), although it should be taken into account that the group that is reduced is the carbonyl group and the nitro group remains intact, which was not our objective.

The best efficiency in the reduction was with (NaBH4, ethanol 85.5\%), although it should be taken into account that the group that is reduced is the carbonyl group and the nitro group remains intact, which was not our objective. The most efficient reaction to reduce only one of the nitro groups, in m-dinitrobenzene, was in the use of 1 gram of sulfur with sodium polysulfide, gives a reasonable result (57\%) compared to the $36 \%$ obtained generally in the teaching laboratories (see practice manual) [18]. In our hands the $10 \% \mathrm{Pd} / \mathrm{C}$ system, with hydrazine 3 (37.56), we were not able to reproduce the performance in the literature $73.89 \%$ of the mononiter $>$ $\mathrm{NH} 4 \mathrm{Cl} / \mathrm{Zn}(31.15 \%)$, is observed graphically (Figure II), that, the one that shows better performance is with polisulfuro of sodium with 1 gram of sulfur, technique implemented by our group of work.

Note: (1) These results were obtained by the students of the Organic Chemistry III (semester 2014-II and 2017-II) and by the professors. Each student performed an experiment (Combinatorial Chemistry).

Mariano Sánchez Mendoza, Adrián Vázquez Sánchez, Consuelo García Manrique, José Gustavo Ávila-Zárraga. "Reduction of Nitro Compounds Using the $\mathrm{Pd} / \mathrm{H}_{2} \mathrm{~N}-\mathrm{NH}_{2} / \mathrm{Mw}$. Education Chemical. System, 24 (3), 347-350, 2013. National Autonomous University of Mexico, ISSN0187-893-X, published online May 14, 2013, ISSNE 1870-8404. 


\section{References}

[1] Burke, S. D., and Danbheiser, R. L. 1999. Handbook of Reagents for Organic Synthesis Oxidizing and Reducing Agents. London, England: Wiley.

[2] Wingrove, A., and Caret, L. R. 1990. Química Orgánica. México: México Oxford University Press.

[3] Kamm, O. 1941. "Synthesis of $\beta$-Phenylhydroxylamine." Organic Syntheses Coll. 1: 445.

[4] Tsukinoki, T., and Tsuzuki, H. 2001. "Organic Reaction in Water. Part. 5. Novel Synthesis of Anilines by Zinc Metal-Mediated Chemoselective Reduction of Nitroarenes." Green Chemistry 3: 37-8.

[5] Entwistle, I. D., Johnstone, R. A. W., and Povall, T. J. 1975. "Selective Rapid Transfer-Hydrogenation of Aromatic Nitro-compounds." Journal of the Chemical Society Perkin I: 1300-1.

[6] Abiraj K, and Gowda, D. C. 2002. "Synthesis and Reactivity." Inorganic and Metal-Organic Chemistry 32 (8): 1409-17.

[7] Entwistle, I. D., Johnstone, R. A. W., and Povall, T. J. 1977. "Reduction of Nitrocompounds." Journal of Chemical Society Perkin I: 443-4.

[8] Rylander, P. N. 1985. Hydrogenation Methods. New York, USA: Academic Press.

[9] Tafesh A. M., and Weiguny, J. 1996. "A Review of selective Catalytic Reduction of Aromatic Nitro Compounds into Aromatic Amines, Isocyanates, Carbamates, and Ureas Using CO.” Chemical Reviews 96: 3035-52.

[10] Petrini, M. 1987. "Reduction of Aliphatic and Aromatic Nitro Compouds with Sodium Borohydride in Tetrahydrofuran Using 10\% Palladium-on Carbon as Catalyst". Dipartimento di Scienze Chimiche, Universita, Via S. Agostino, 1, I-62032 Camerino, Italy.

[11] Wade, R. C. 1983. J. Mol. Catalysis 18: 273.
[12] Kamm, O. 1973. "Synthesis of 2-Aminofluorene." Organic Syntheses Coll. 5: 30.

[13] Jerry, R. 1998. "Mohring and Christina Noring Hammond, Macroscale and Microscale." Experimental Organic Chemistry, 202-9.

[14] Ávila, J. G., Gavilán, I. C., and Cano, G. S. 2011. "Teoría y Experimentos de Química Orgánica con un Enfoque de Química Verde.” México: Universidad Nacional Autonóma de México.

[15] MacClelland, R. A., Panicucci, R., and Rauth, A. M. 1987. "Products of the Reductions of 2 Nitroimidazoles." J. Am. Soc. 109: 4308-14.

[16] Mohring, J. R., Morrill, T. V., Hammond, C. N., and Neckers, D. C. Experimental Organic Chemistry: A Balanced Approach Macroscale and Microescale. W.H. Freeman and Company.

[17] Mendoza, M. S., Sánchez, A. V., Manrique, C. G., and Ávila-Zárraga, J. G. 2013. "Reduction of Nitro Compounds Using the $\mathrm{Pd} / \mathrm{H}_{2} \mathrm{~N}-\mathrm{NH}_{2} / \mathrm{Mw}$ System." Green Chemistry, Educ. Quim. 24 (3): 347-50.

[18] Sánchez Mendoza, A. D. 2017. "Manual of Experimental Organic Chemistry III." Department of Organic Chemistry, Faculty of Chemistry, UNAM.

[19] Hodgson, H, H., and Ward, E. R. 1947. "Some Reactions and Derivatives of 6- and 7-Nitro-2-Naphthylamines. Part II. Nitration and Diazo-Coupling." J. Chem. Soc. 242: 1060-2.

[20] Doyle, M. P., and Mungall, W. S., ed., 1980. Experimental Organic Chemistry. John Wiley \& Sons.

[21] Carey Francis, A. 2006. Quimica Organica. McGraw Hill Interamericana.

[22] Clayden, H., Greeves, N., and Warren, S. 2001. Organic Chemistry. Oxford University Press.

[23] Vogel, A. et al. 1996. Vogel's. Textbook of Practical Organic Chemistry (5th ed.). Prentice Hall. 